\title{
Manage Socially: The Social Process Model
}

\section{Eli Saad*}

IPADE Business School, UNC Chapel Hill, Austin, Texas, US

"Your work is better managed socially when connected to its uncontrolled relationships: impacts and assumptions. We do it in 5-step Social Process Model”.

\section{Why? Because the World is Changing}

The ecosystem in which work gets done is becoming more and more connected. People reaching information goods and other people is taking less time (and money). That means we can now strategize at the personal level. Yes! a personal scorecard that contributes to the organizational one. Just like organizations improved performance by using scorecards to manage their work in relation to their ecosystem, we can now improve work at the personal level .

The signals are everywhere: crowdsourcing, holacracy, specialization, mobility It's all about making relevant connections. To experience this I propose a 5step model based on the natural flow of work. It's called The Social Process Model, and you already do $30 \%$ of it (Figure 1).

Who is this for? If you want to show your contribution to the organizational goals and discover how irreplaceable your role, this model is for you! If you want to demonstrate attribution, meaning you are the reason why your boss or clients are happy, this mode is for you! If you think you can manage the uncontrolled assumptions to your and your client's favor, this model is for you! The thing is explained in Figures 2 and 3.

\section{How? The 3 Social Dimensions of Work}

It's common today to see that one BIG PLAN and uncommon to see the personal one. I mean to go beyond the job description and the calendar. When coming up with a model that follows work naturally

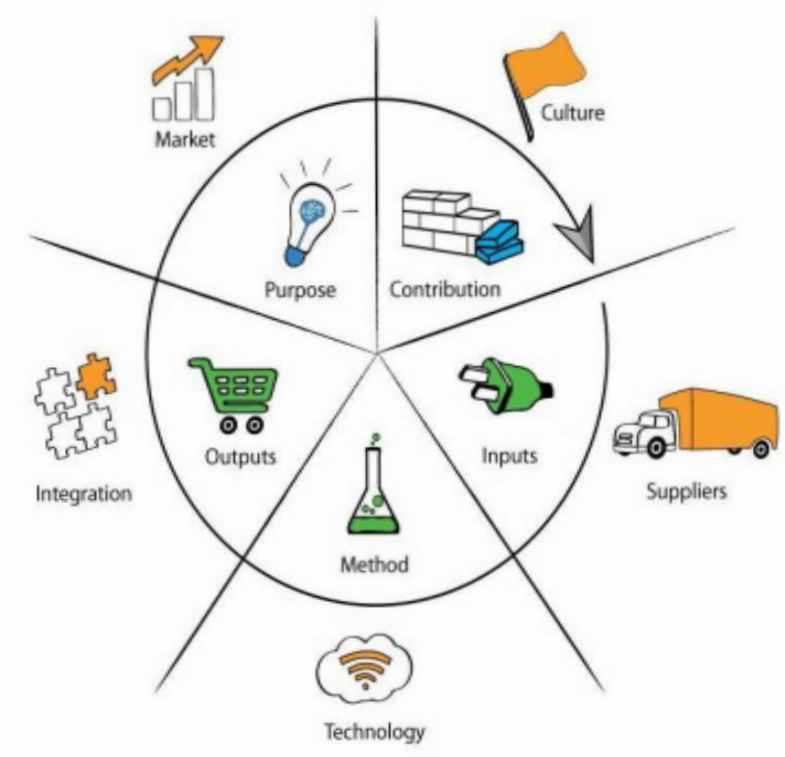

Figure 1: Social Process Model.

we observed three phases: we receive to transform, we deliver to make a change and we depend on other people's work. In other words we process, impact as assume, these are the basic dimensions of how we experience work. In that Big Plan meeting the friction points are:

The BIG Plan goals don't easily relate to personal level goals.

The client's/boss changes are given small attention.

Assumptions are left to fate.

The Social Process Model began by positively stating them:

Apply the BIG plan at a personal level through connected PROCESSES Describe how beneficiaries will be transformed as IMPACT.

Trackassumptionsthatfavorusand ourclients as ASSUMPTIONS.

\section{What? A 5 Step Social Model}

The Social Process Model recognizes how you experience the three dimensions of work in a 5 step mindset: inputs, method, outputs, purpose and contribution. It's circular because you can start working

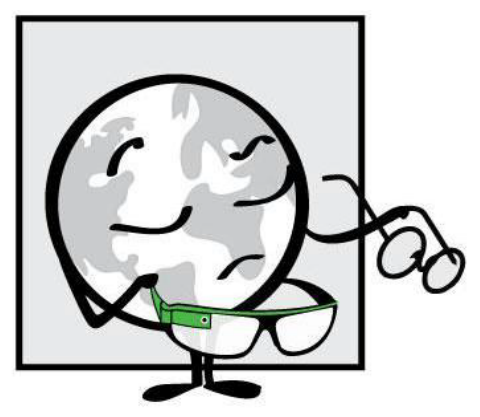

Figure 2: World is Changing
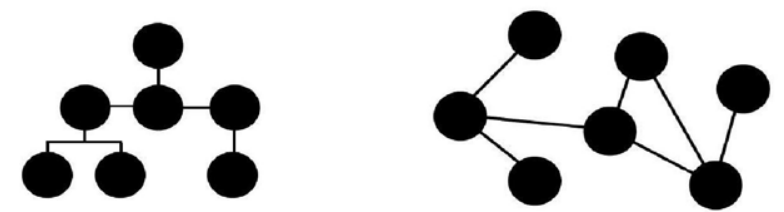

Figure 3: Manage LESS like this, and MORE like this.

*Corresponding author: Eli Saad, IPADE Business School, UNC Chapel Hill, Austin, Texas, US, Tel: +52 (55) 5354-1800; E-mail: e.saad@uncbusiness.net

Recieved July 17, 2015; Accepted July 27, 2015; Published August 07, 2015

Citation: Saad E (2015) Manage Socially: The Social Process Model. J Entrepren Organiz Manag 4: 145. doi:10.4172/2169-026X.1000145

Copyright: (c) 2015 Saad E. This is an open-access article distributed under the terms of the Creative Commons Attribution License, which permits unrestricted use, distribution, and reproduction in any medium, provided the original author and source are credited. 


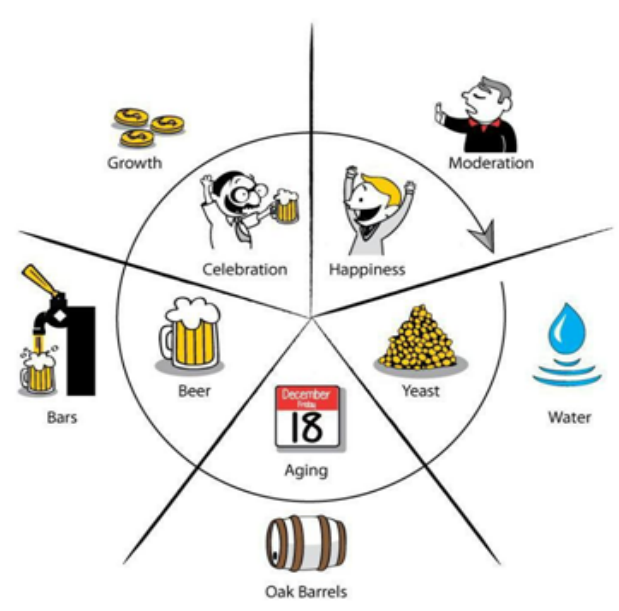

Figure 4: For example: Beer.

in it anywhere and connect each part to other models, and because it's the optimal design by nature: planets, cells. Each one of the 5 steps has a corresponding assumption which you depend on happening, like new generation drones needing longer lasting batteries shown in Figure 4.

In other words, a 'process' will generate the desired impact, if uncontrolled assumptions become true. The Process part of the Model is made of: inputs, method and outputs. The Impact is made of purpose and contribution. All five goals or steps have a corresponding Assumption.

Analyzing the 'Impact' in two levels solves our task of giving beneficiaries adequate attention, because it requires understanding how you change your client's situation, and how that change contributes to a higher goal. In other words, purpose is a direct impact generated, and the contribution is an indirect impact.

The 'Process' components: inputmethodoutput are a no brainer, but when thinking socially they make it easier to understand how the outputs of one process become the inputs of other process(es) and they other way around. Now you can apply the BIG Plan at a personal and group level.

Finally, the 'Assumptions' are the complement to each part of the process and impact. This means they are positive actions we depend on, but are out of our control. We can choose to influence, complement or any other way of making it happen (Figure 1).

\section{The Next Steps}

Strategize at the personal level! That's the next phase in the management trend. Either your model or the Social Process Model. My suggestion: make the tool fit the hand, so you can treat work as a workout.

\section{Now move it!}

... move your work

... move your ecosystem, Socially! 